\title{
Penggunaan Kerangka Kerja COBIT 4.1 Sebagai Hasil Evaluasi Pengelolaan Teknologi Informasi CV. INDOJAYA
}

\author{
Wishnu Aribowo Probonegoro*1, Lili Indah Sari ${ }^{2}$, Parlia Romadiana ${ }^{3}$ \\ ${ }^{1,2,3}$ ISB Atma Luhur; Jl. Jendral Sudirman Pangkalpinang, (0717) 433506 \\ ${ }^{1, J}$ Jurusan Sistem Informasi, ${ }^{2,3}$ Jurusan Manajemen Informatika,Fakultas Teknologi Informasi \\ ISB Atma Luhur \\ e-mail: ${ }^{1}{ }^{1}$ wishnuap77@ atmaluhur.ac.id, ${ }^{2}$ lilie@ atmaluhur.ac.id, \\ ${ }^{3}$ parliaromadiana@atmaluhur.ac.id
}

\begin{abstract}
Abstrak
Peranan, pengaruh dan penggunaan teknolgi informasi saat ini berdampak bagi semua perusahaan, termasuk CV Indojaya. CV. INDOJAYA merupakan perusahaan manufaktur ban vulkanisir sekaligus distributor ke berbagai daerah di provinsi Bangka Belitung. Penggunaan teknologi informasi memiliki potensi yang menjadi penentu kesuksesan, keberhasilan, untuk mendapatkan keunggulan yang kompetitif bagi perusahaan. Peningkatan penggunaan teknologi informasi harus berbanding lurus dengan investasi yang sudah dikeluarkan. Untuk itu diperlukan adanya tata kelola teknologi informasi yang baik, dengan mengevaluasi penggunaan tata kelola ti. Agar investasi untuk Teknologi Informasi yang sudah dikeluarkan oleh CV Indojaya sebanding dengan tujuan, maka CV Indojaya harus menerapkan Tata Kelola Teknologi Informasi yang baik. Saat ini CV Indojaya sudah menggunakan dan melakukan penerapan pengelolaan teknlogi informasi, tetapi belum pernah dilakukan evaluasi terhadap pengelolaan teknlogi informasi yang ada. Oleh karena itu perlu dilakukan evaluasi pengelolaan teknologi informasi dengan menggunkan kerangka kerja COBIT 4.1. Karena COBIT (Control Objective for Information and Related Technology) memiliki kerangka kerja teknologi informasi dan memberikan panduan berdasarkan praktik terbaik menurut ISACA,Kepada manajer, auditor, pengguna (user) untuk menjembatani aspek bisnis, kebutuhan kontrol dan teknis TI. Hasil dari penelitian ini dengan menggunaka pengukuran maturity level, bahwa CV Indojaya saat ini masih berada di level 2 yaitu Repeatable level
\end{abstract}

Kata kunci Tata Kelola, Cobit 4.1, Maturity Level, Evaluasi, Teknologi Informasi

\begin{abstract}
The role, influence and use of information technology today impacts all companies, including CV Indojaya. CV. INDOJAYA is a retread tire manufacturing company as well as a distributor to various areas in the province of Bangka Belitung. The use of information technology has the potential to determine success, success, to gain a competitive advantage for the company. Increased use of information technology must be directly proportional to the investment that has been issued. For this reason, it is necessary to have good information technology governance, by evaluating the use of IT governance. In order for the investment in Information Technology that has been issued by $C V$ Indojaya to be comparable to the objectives, CV Indojaya must implement good Information Technology Governance. Currently CV Indojaya has used and implemented the management of information technology, but there has never been an evaluation of the management of existing information technology. Therefore, it is necessary to evaluate the management of information technology using the COBIT 4.1 framework. Because COBIT (Control Objective for Information and Related Technology) has an information technology framework and provides guidance based on best practices according to ISACA to managers, auditors, users to bridge business aspects, IT control and technical
\end{abstract}


needs. The results of this study using the measurement of maturity level, that CV Indojaya is currently still at level 2, namely Repeatable level,

Keywords Governance, Cobit 4.1, Maturity Level, Evaluation, Information Technology

\section{PENDAHULUAN}

$\mathrm{T}$ eknologi informasi setiap saat selalu mengalami perkembangan yang luar biasa pada berbagai sektor kehidupan manusia. Peranan, pengaruh dan penggunaan teknolgi informasi saat ini berdampak bagi semua perusahaan, termasuk CV Indojaya. Saat ini hampir semua perusahaan menggunakan dan sudah mengimplematasi kan teknlogi informasi dalam semua kegiatannya, karena penerapan teknologi informasi untuk menunjang proses bisnis perusahaan,meningkatkan produktivitas, kinerja perusahaan dan memberikan manfaat yang lebih dimasa yang akan datang. Hal ini membutuhkan perencanaan yang matang sampai dengan implementasinya dalam menjalankan investasi terknologi informasi nantinya.

Penggunaan teknologi informasi memilik potensi yang menjadi penentu kesuksesan, keberhasilan, untuk mendapatkan keunggulan yang kompetitif bagi CV Indojaya. Memberikan peluang-peluang untuk meningkatkan produktivitas bisnis yang sedang berjalan dan keuntungan bagi CV Indojaya. Di sisi lain keterlibatan dan penggunaan teknologi informasi dalam suatu perusahaan memerlukan biasa yang besar dan mahal, serta kemungkinan terjadinya resiko kegagalan yang cukup tinggi. Peningkatan penggunaan teknologi informasi harus berbanding lurus dengan investasi yang sudah dikeluarkan. Untuk itu diperlukan adanya tata kelola teknologi informasi yang baik pada CV Indojaya di mulai dari perencanaan sampai dengan implementasinya, agar CV Indojaya dapat berjalan dengan optimal.

Agar investasi untuk Teknologi Informasi yang sudah dikeluarkan oleh CV Indojaya sebanding dengan tujuan yang akan dipakai CV Indojaya,maka CV Indojaya harus menerapkan Tata Kelola Teknologi Informasi yang baik. Saat ini CV Indojaya sudah menggunanakan dan melakukan penerapan pengelolaan teknlogi informasi, tetapi belum pernah dilakukan evaluasi terhadap pengelolaan teknlogi informasi yang ada. Dalam penelitian ini standar yang digunakan adalah standar COBIT (Control Objective for Information and Related Technology). Karena COBIT (Control Objective for Information and Related Technology) memiliki kerangka kerja teknologi informasi dan memberikan panduan berdasarkan praktik terbaik menurut ISACA kepada manajer, auditor, pengguna (user) untuk menjembatani aspek bisnis, kebutuhan kontrol dan teknis TI. [1]. Institusi Pendidikan pastinya membutuhkan pengelolaan teknologi informasi dalam menunjang sarana pendidikan, termasuk Universitas Pendidikan Indonesia (UPI).Teknolgi Informasi sebagi modal utama dalam meingktakna kualitas dan daya saing global,untuk dapat mengetahui sudah sejauh mana penggunaan dan pengelolaan teknologi informasi yang ada ada di UPI, maka diperlukan evaluasi terhadap pengelolaan tata kelola yang ada, berdasarkan data tersebut, maka tujuan penelitian ini untuk mengidentifikasi indicator dan mengetahui evaluasi tata kelola ti yang ada dengan menggunakan COBIT [2]. PT. Aneka Solusi Teknologi adalah perusahaan penyedia jasa perbaikan kualitas serta penyelesaian masalah yang terjadi pada elektronik, komputer dan mobile phone dengan cakupan layanan nasional. Audit dilakukan untuk analisis dan mengetahui keamanan dan integritas data dari sistem informasi yang digunakan dengan menggunakan framework COBIT 4.1. Tujuan dari penelitian ini adalah untuk mengevaluasi dan menjadikan hasil audit sebagai masukan untuk memperbaiki pengelolaan sistem berjalan pada perusahaan tersebut. Dari hasil penelitian menyimpulkan bahwa sistem informasi yang terdapat pada PT. Aneka Solusi Teknologi masih terdapat kekurangan dalam tata kelola ITnya [3] 


\section{METODE PENELITIAN}

\subsection{Kerangka Kerja COBIT}

Penggunaan Kerangka Kerja COBIT 4.1 Sebagai Hasil Evaluasi Pengelolaan Teknologi Informasi pada perusahaan dikarenakan COBIT (Control Objectives for Information and Related Technology) adalah standar untuk informasi dan teknologi yang menyertainya yang berlaku internasional. Sebagai sebuah framework yang mengatur pengelolaan informasi, COBIT memiliku standar pengelolaan informasi yang terbagi dalam 4 domain, yaitu: Plan and Organize (PO), Acquire and Implement (AI), Delivery and Support (DS), dan Monitoring and Evaluate (ME). [4], [5]

\section{BUSINESS QBJECTIVES}

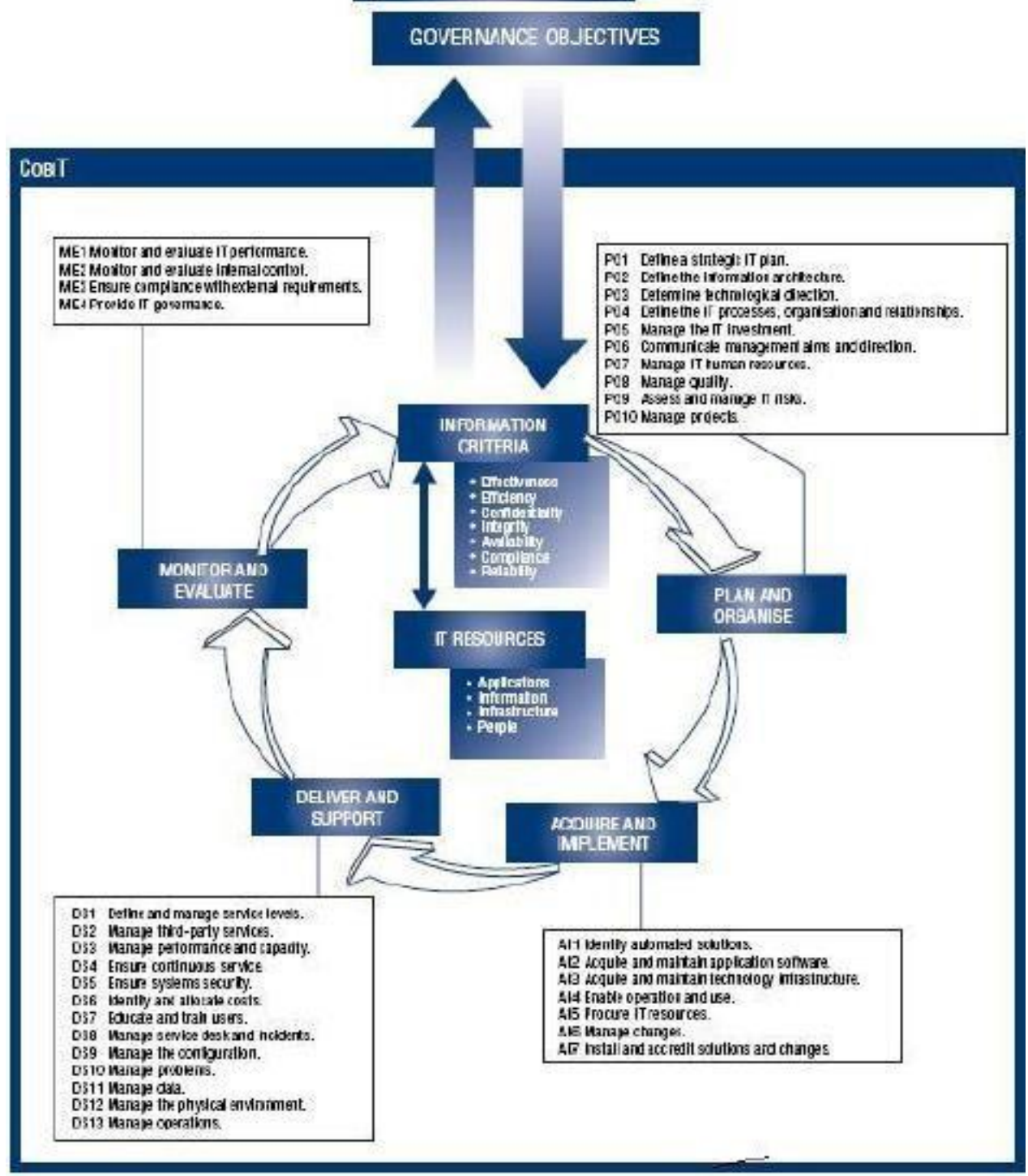

Gambar 1. Framework COBIT [5]

COBIT mendefiniskan Control objective IT sebagai pernyataan mengenai hasil atau tujuan yang harus dicapai melalui penerapan prosedur kendali dalam aktivitas TI tertentu. Pada edisi keempat ini COBIT framework terdiri dari 34 high level control objectives dikelompokkan dalam 4 domain utama, bisa dilihat pada Gambar 1. Framework COBIT [5], [6] 
2.2 Model Kematangan COBIT (Control Objectives for Information and Related Technology)

Model kematangan (maturity model) digunakan sebagai alat untuk melakukan benchmarking dan self-assessment oleh manajemen teknologi informasi secara lebih efisien. Model kematangan untuk pengelolaan dan kontrol pada proses teknologi informasi didasarkan pada metoda evaluasi perusahaan atau organisasi, sehingga dapat mengevaluasi sendiri, mulai dari level 0 (non-existent) hingga level 5 (optimised).[7]

Representasi tingkat kematangan COBIT dapat dilihat yaitu

Tabel 1. Indeks Kematangan

\begin{tabular}{|c|c|}
\hline $\begin{array}{c}\text { Framework COBIT 4.1 } \\
\text { Indeks Kematangan }\end{array}$ & \multicolumn{1}{c|}{ Level Kematangan } \\
\hline $0-0,5$ & $0:$ Non Existent (Tidak Ada) \\
\hline $0,51-1,5$ & $1:$ Initial /Ad Hoc (Inisial) \\
\hline $1,51-2,5$ & $\begin{array}{c}2: \text { Repeatable But Intuitive } \\
\text { (Pengulangan proses } \\
\text { berdasarkan intuisi) }\end{array}$ \\
\hline $2,51-3,5$ & $\begin{array}{c}3: \text { Defined Process (Proses } \\
\text { telah didefinisikan) }\end{array}$ \\
\hline $3,51-4,5$ & $\begin{array}{c}4: \text { Managed and Measurable } \\
\text { (Dikelola dan terukur) }\end{array}$ \\
\hline $4,51-5$ & $5:$ Optimised (Optimalisasi) \\
\hline
\end{tabular}

COBIT mempunyai model kematangan untuk mengontrol proses-proses TI dengan menggunakan metode penilaian (scoring) sehingga organisasi dapat menilai proses-proses TI yang dimilikinya". Dengan adanya maturity level model, maka organisasi dapat mengetahui posisi kematangannya saat ini, dan secara terus menerus serta berkesinambungan harus berusaha untuk meningkatkan levelnya sampai tingkat tertinggi agar aspek tata kelola terhadap teknologi informasi dapat berjalan secara efektif. [8]

Generic Maturity Model terdiri dari: [8]

0- Non Existent- Perusahaan sama sekali tidak peduli akan pentingnya teknologi informasi untuk kelola secara baik oleh pihak manajemen.

1- Initial /Ad Hoc- Perusahaan secara reaktif melakukanpenerapan danimplementasi teknologi informasi sesuai dengan kebutuhan-kebutuhan mendadak yang ada, tanpa didahului dengan perencanaan sebelumnya.

2- Repeatable but Intituitive - Perusahaan telah memiliki pola yang berulangkali dilakukan dalam melakukan manajemen aktivitas terkait dengan tata kelola teknologi informasi, namun keberadaannya belum terdefinisi secara baik dan formal sehingga masih terjadi ketidak konsistenan.

3- Defined - Perusahaan telah memiliki prosedur baku formal dan tertulis yang telah disosialkan ke segenap jajaran manajemen dan karyawan untuk dipatuhi dan dikerjakan dalam aktivitas sehari-hari.

4- Managed and Measurable - Perusahaan telah memiliki sejumlah indikator atau ukuran kuantitatif yang dijadikan sebagai sasaran maupun objektif kinerja setiap penerapan aplikasi teknologi informasi yang ada.

5- Optimised - Perusahaan telah mengimplementasikan tata kelola teknologi informasi yang mengacu pada "Best Practice". 


\section{HASIL DAN PEMBAHASAN}

\subsection{Teknik Pengumpulan Data}

Penulis melakukan beberapa tahapan dalam melakukan penelitian ini diantaranya yaitu melakukan wawancara, observasi,kuesioner, dimana kegiatan pemusatan perhatian terhadap sesuatu objek dengan menggunakan alat indera. [9]. Setelah ini membuat dan membagikan kuesioner kepada responden, kuesioner merupakan serangkaian pertanyaan yang disusun secara sistematis untuk diisi oleh responden, dan kemudian setelah diisi dikembalikan ke peneliti[10]

\subsection{Metodologi Penelitian}

Dalam penelitian ini penulis menggunakan data deskriptif yaitu suatu penelitian yang bertujuan untuk menggambarkan sesuatu yang berlangsung pada saat penelitian dilakukan dan memeriksa sebab-sebab dari suatu gejala tertentu. [11]. Penelitian ini juga merupakan peneliti kualitatif sebagai human instrumen, berfungsi menetapkan fokus penelitian, memilih informan sebagai sumber data, melakukan pengumpulan data, menilai kualitas data, menafsirkan data dan membuat kesimpulan atas temuannya.[12]. Penulis menggunakan penelitian kualitatif. Karena data dan informasi yang penulis kumpulkan lebih banyak bersifat keterangan-keterangan atau penjelasan yang bukan berbentuk angka. Metode kualitatif menggunakan studi kasus (objek), yaitu suatu cara yang sistematis dalam melihat suatu kejadian, mengumpulkan data, menganalisa informasi dan melaporkan hasilnya. Karena penulis menggunakan metode kualitatif dengan studi kasus, maka teknik sampling menggunakan non probability sampling dengan teknik pengambilan purposive sampling. Purposive sampling dipilih oleh penulis karena pengumpulan sampel yang diambil dengan maksud dan tujuan tertentu, pengambilam responden secara sengaja, dimana responden dipilih karena kompeten di bidangnya.

Adapun desain penelitian yang dilakukann oleh penulis, digambarkan sebagai berikut:

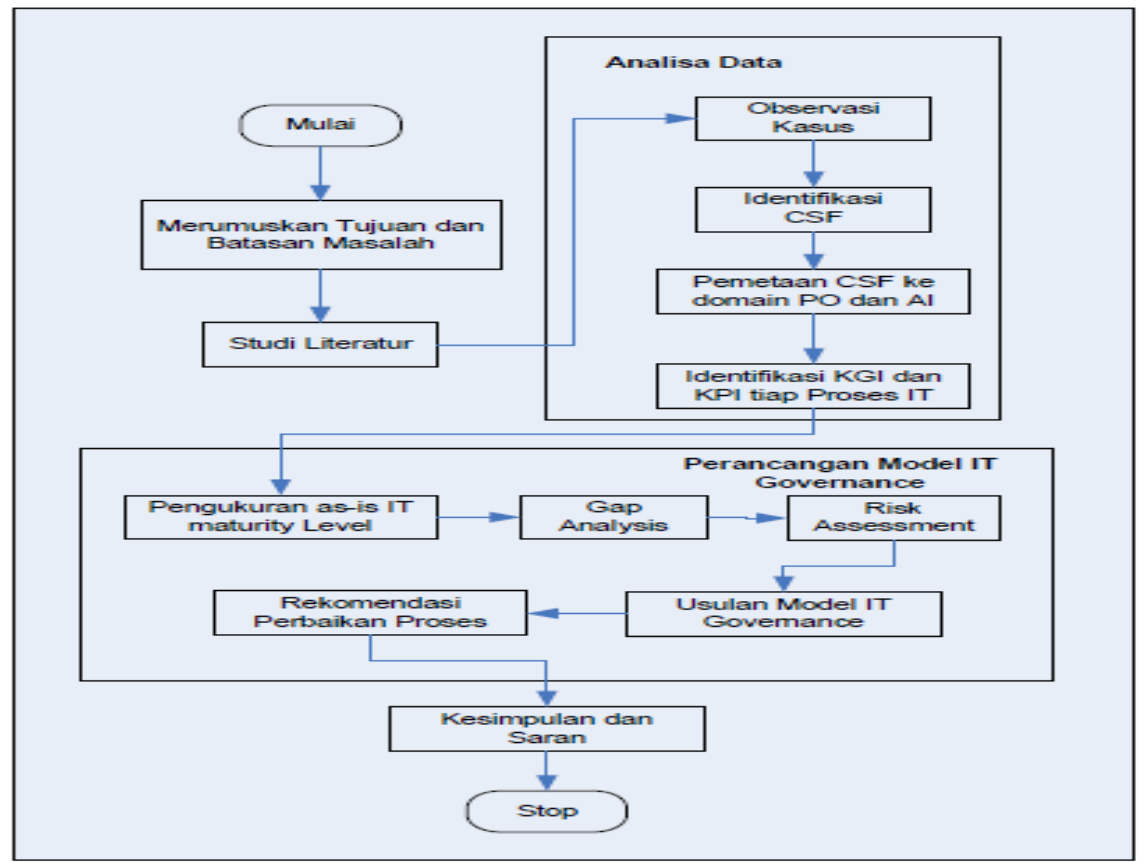

Gambar 2. Desain Penelitian

Tahapan-tahapan penulis terhadap penelitian ini adalah sebagai berikut: Langkah 1: Identifikasi CSF (Critical Success Factor) 
Tahapan ini akan menjelaskan Tujuan, sasaran, visa dan misi yang ada di CV Indojaya. Dan melengkapi Bussiness goal secara detail terhadap CV tersebut. Pemetaan dilakukan dari CSF yang ada di CV Indojaya ke CSF yang ada di Cobit 4.1 yang memiliki 4 perspektif

Tabel 2. Pemetaan CSF CV Indojaya ke CSF Cobit 4.0

1. Mendukung laju pertumbuhan ekonomi
Kepulauan Bangka Belitung dan dunia
pariwisatanya.
2. Menjadi produsen penghasil ban yang bisa
memenuhi kepuasan pelanggan.
3. CV. INDOJAYA telah memiliki angaran untuky
mempersiapkan pembangunan IT.
4. CV. INDOJAYA telah memiliki infrastruktur
perangkat keras dan lunak yang dibeli dari
anggaran sendiri.
5. CV. INDOJAYA telah menggunakan layanan
berbasis IT dan terkomputerisasi untuk melavani
pelanggan.

Langkah 2: Identifikasi IT Goals

IT goals di perolah dari hasil pemetaan terhadap Critical Success Factor yang terdapat pada Cobit.

Tabel 3. Pemetaan Terhadap IT Goals

\begin{tabular}{|c|l|}
\hline \multicolumn{2}{|c|}{ IT Goals CV. INDOJAYA } \\
\hline 3 & Ensure satisfaction of end users with service offerings and service \\
9 & levels \\
16 & Acquire and maintain IT skills that respond to the IT strategy. \\
22 & Reduce solution and service delivery defects and rework. \\
23 & Ensure minimum business impact in the event of an IT service \\
24 & disruption or change. \\
25 & Make sure that IT services are available as required. \\
28 & Improve IT's cost-efficiency and its contribution to business \\
& profitability. \\
& Deliver projects on time and on budget, meeting quality standards. \\
& Ensure that IT demonstrates cost-efficient service quality, continuous \\
& improvement and readiness for future change. \\
\hline
\end{tabular}


Langkah 3: Identifikasi IT Process / CSF Mapping

Tahap ini mengidentifikasikan IT Goals menjadi IT Process sesuai dengan standard Cobit 4.1

Tabel 4. CSF Mapping

\begin{tabular}{|c|c|c|c|c|c|c|c|c|c|}
\hline \multicolumn{2}{|r|}{ IT Goals CV. INDOJAYA } & \multicolumn{8}{|c|}{ IT Process } \\
\hline 3 & Ensure satisfaction of end users with & PO8 & AI4 & DS1 & DS2 & DS7 & DS8 & DS10 & DS13 \\
\hline & service offerings and service levels & & & & & & & & \\
\hline 9 & $\begin{array}{l}\text { Acquire and maintain IT skills that } \\
\text { respond to the IT strategy. }\end{array}$ & $\mathrm{PO} 7$ & AI5 & & & & & & \\
\hline 16 & $\begin{array}{l}\text { Reduce solution and service delivery } \\
\text { defects and rework. }\end{array}$ & POS & AI4 & AI6 & AI7 & DS10 & & & \\
\hline 22 & $\begin{array}{l}\text { Ensure minimum business impact in } \\
\text { the event of an IT service disruption } \\
\text { or change. }\end{array}$ & PO6 & AI6 & DS4 & DS12 & & & & \\
\hline 23 & $\begin{array}{l}\text { Make sure that IT services are } \\
\text { available as required. }\end{array}$ & DS3 & DS4 & DS8 & DS13 & & & & \\
\hline 24 & $\begin{array}{l}\text { Improve IT's cost-efficiency and its } \\
\text { contribution to business profitability. }\end{array}$ & PO5 & DS6 & & & & & & \\
\hline 25 & $\begin{array}{l}\text { Deliver projects on time and on } \\
\text { budget, meeting quality standards. }\end{array}$ & POS & PO10 & & & & & & \\
\hline 28 & $\begin{array}{l}\text { Ensure that IT demonstrates cost- } \\
\text { efficient service quality, continuous } \\
\text { improvement and rea diness for future } \\
\text { change. }\end{array}$ & PO5 & DS6 & ME1 & ME4 & & & & \\
\hline
\end{tabular}

Langkah 4: Identifikasi Control Objectives / KGI dan KPI

It Process yang diperoleh dari penelitian ini sebanyak 20 it proses

Langkah 5: Maturity Level

Maturity Level merupakan perhitungan tingkat kedewasaan yang dilakukan oleh penulis, perhitungan ini merupakan perhitungan akhir, guna mendapatkan nilai yang sesuai dengan yang terdapat pada cobit 4.1 .

Perhitungan tingkat kedewasan yang dilakukan penulis berdasarkan dari kuesioner yang sudah diisi oleh responden dengan menggunakan model kematangan pada cobit 4.1. Berikut ini adalah hasil dari perhitungan tingkat kematangan berdasarkan domain masing-masing yang terdapat di COBIT 4.1

Hasil Perhitungan Tingkat Kedewasaan

Tabel 5. Tingkat Kedewasaan pada Domain Plan and Organize

\begin{tabular}{|c|l|c|c|}
\hline Domain & \multicolumn{1}{|c|}{ PROSES } & $\begin{array}{c}\text { Current } \\
\text { Maturity }\end{array}$ & $\begin{array}{c}\text { Expected } \\
\text { Maturity }\end{array}$ \\
\hline PO5 & $\begin{array}{l}\text { Manage the IT } \\
\text { investment }\end{array}$ & 2.566 & 3 \\
\hline PO6 & $\begin{array}{l}\text { Communicate } \\
\text { Management Aims and } \\
\text { Direction }\end{array}$ & 3.068 & 3 \\
\hline PO7 & $\begin{array}{l}\text { Manage IT Human } \\
\text { Resources }\end{array}$ & 2.292 & 3 \\
\hline
\end{tabular}




\begin{tabular}{|c|l|l|l|} 
PO8 & Manage Quality & 2.160 & 3 \\
\hline PO10 & Manage projects & 2.093 & 3 \\
\hline \multicolumn{2}{|c|}{ Total } & 2.029 & \\
\hline
\end{tabular}

Proses yang diteliti penulis terhadap domain PO (Plan and Organize), nilai kematangan tertinggi ada di PO6 (Communicate Management Aims and Direction) dengan nilai 3.068 dan berada di level 3 yaitu Defined Process. Hal ini menjelaskan bahwa komunikasi, tujuan dan arahan manajemen tentang pengelolaan teknologi informasi sudah memiliki prosedur baku yang formal dan tertulis serta disosialisasikan di jajaran manajemen dan karyawan [6]. Sedangkan nilai terkecil terdapat pada PO10(Manage projects), perusahaan dalam mengatur dan mengelola proyek teknlogi informasi khususnya belum memiliki pola dan arahan yang baik. Perusahaan harus bisa meningkatkan pelaksanaa pelatihan manajemen proyek kepada seluruh pihak TI dan staf

Tabel 6. Tingkat Kedewasaan pada Domain Acquire and Implementation

\begin{tabular}{|c|l|c|c|}
\hline Domain & \multicolumn{1}{|c|}{ PROSES } & $\begin{array}{c}\text { Current } \\
\text { Maturity }\end{array}$ & $\begin{array}{c}\text { Expected } \\
\text { Maturity }\end{array}$ \\
\hline AI4 & Enable Operation and Use & 2.611 & 3 \\
\hline AI5 & Procure IT Resources & 2.573 & 3 \\
\hline AI6 & Manage Changes & 2.095 & 3 \\
\hline AI7 & $\begin{array}{l}\text { Install and Accredit } \\
\text { Solutions and Changes }\end{array}$ & 2.152 & 3 \\
\hline \multicolumn{2}{|c|}{ Total } & 2.357 & \\
\hline
\end{tabular}

Pada domain AI (Acquire and Implementation), berdasarkan perhitungan menggunakan nilai kematangan cobit 4.1, Level tertinggi berada pada AI4 yaitu Enable Operation and Use dengan nilai kedewasaan adalah 2.611.Sedangkan nilai tingkat kematangan terkecil terdapat pada AI6 yaitu Manage Changes dengan nilai 2.095. sehingga nilai rata - rata keseluruhan yang terdapat pada domain AI (Acquire and Implement) yaitu sebesar 2.357, yang berada di level 2, dimana dalam mengelola perubahan, menyediakan sumberdaya teknlogi informasi, mengaktifkan operasi dan penggunaan teknologi informasi, instalasi dan akreditasi solusi dalam perubahan didalam perusahaan belum berjalan dengan baik dan maksimal sehingga bisa terjadi ketidak konsistenan dalam melakukannya.

Tabel 7. Tingkat Kedewasaan pada Domain Deliver and Support

\begin{tabular}{|c|l|c|c|}
\hline Domain & \multicolumn{1}{|c|}{ PROSES } & $\begin{array}{c}\text { Current } \\
\text { Maturity }\end{array}$ & $\begin{array}{c}\text { Expected } \\
\text { Maturity }\end{array}$ \\
\hline DS1 & Define and manage service levels & 1.803 & 3 \\
\hline DS2 & Manage Third-party Services & 2.435 & 3 \\
\hline DS4 & Ensure continous service & 2.595 & 3 \\
\hline DS6 & Identify and Allocate Costs & 2.233 & 3 \\
\hline DS7 & Educate and Train Users & 3.348 & 3 \\
\hline
\end{tabular}




\begin{tabular}{|c|l|c|c|} 
DS8 & $\begin{array}{l}\text { Manage Service Desk and } \\
\text { Incidents }\end{array}$ & 2.283 & 3 \\
\hline DS10 & Manage problems & 2.342 & 3 \\
\hline DS12 & $\begin{array}{l}\text { Manage the Physical } \\
\text { Environment }\end{array}$ & 2.400 & 3 \\
\hline DS13 & Manage Operations & 2.970 & 3 \\
\hline \multicolumn{2}{|c|}{ Total } & 2.489 & \\
\hline
\end{tabular}

Nilai rata-rata yang dihasilkan oleh domain DS (Deliver and Support) sebesar 2.489 berada pada level 2 (Repeatable but Intituitive level), maksudnya Perusahaan telah memiliki pola yang berulangkali dilakukan dalam melakukan manajemen aktivitas terkait dengan pengelolaan teknologi informasi, namun keberadaannya belum terdefinisi secara baik dan formal sehingga masih terjadi ketidak konsistenan. [6]. Dari level 2 yang ada pada domain DS, DS 7 yaitu Educate and Train Users memperoleh nilai tertinggi dengan nilai 3.348, dalam hal ini perusahaan sudah bisa mendidik dan melatih pengguna dengan baik. Nilai terkecil yang dihasilkan pada domain DS ini terdapat pada DS1 (Define and manage service levels )dengan nilai 1.803, bahwa manajemen perusahaan masih belum terlalu menyadari penting meningkatkan mutu layanan kepada pelanggan, proses pengembangan service level agreement masih belum terlalu diperhatikan dan pengelolaan mutu layanan kebanyakan belum di sesuaikan dengan kebutuhan bisnis dan penggunaan teknologi informasi.

Tabel 8. Tingkat Kedewasaan pada Monitor and Evaluate

\begin{tabular}{|c|l|c|c|}
\hline Domain & PROSES & $\begin{array}{c}\text { Current } \\
\text { Maturity }\end{array}$ & $\begin{array}{c}\text { Expected } \\
\text { Maturity }\end{array}$ \\
\hline ME1 & $\begin{array}{l}\text { Monitor and Evaluate IT } \\
\text { Performance }\end{array}$ & 2.624 & 2 \\
\hline ME4 & Provide IT Governance & 0.000 & 2 \\
\hline \multicolumn{2}{|c|}{ Total } & 1.312 & \\
\hline
\end{tabular}

Pada domain ME, ada 2 (dua) proses yang berhasil dilakukan perhitungan tingkat kematangannya yaitu pada ME1 dan ME4. Level tertinggi berada pada ME1 yaitu Monitor and Evaluate IT Performance, perusahaan sudah merencanakan dan melaksanakan dengan cukup baik tentang pelaksanaan pengawasan dan evaluasi terhadap kinerja divisi maupun perangkat teknologi di perusahaan tersebut. Sedangkan tingkat kedewasaan ada pada ME4 (Provide IT Governance) dengan nilai 0.000 , hal ini menunjukan bahwa manajemen sebenarnya belum mempunyai kesiapan untuk dialkukannya audit secara independen oleh pihak lain. Adapun nilai rata-rata atau total masih agak kurang yaitu 1.312.

Tabel 9. Tingkat Kedewasaan CV. INDOJAYA

\begin{tabular}{|c|l|c|c|}
\hline Domain & \multicolumn{1}{|c|}{ PROSES } & $\begin{array}{c}\text { Current } \\
\text { Maturity }\end{array}$ & $\begin{array}{c}\text { Expected } \\
\text { Maturity }\end{array}$ \\
\hline PO & Plan and Organize & 2.029 & 3 \\
\hline DS & Delivery and Support & 2.357 & 3 \\
\hline AI & Acquire and Implement & 2.489 & 3 \\
\hline
\end{tabular}




\begin{tabular}{|c|c|c|c|} 
ME & Monitor and Evaluate & 1.312 & 2 \\
\hline Total & $\mathbf{2 . 0 4 6}$ & \\
\hline
\end{tabular}

Berdasarkan hasil penelitian ini,dapat kita lihat pada table keseluruhan tentang perhitungan maturity level yang ada pada CV.Indojaya yang meliputi empat domain yaitu Plan and Organize(PO), Delivery and Support (DS), Acquire and Implement(AI), Monitor and Evaluate(ME), semuanya berada di level 2 untuk current maturity levelnya,sedangkan nilai expected maturity (yang diharapkan) 3. Dan total keseluruhan ada di level 2 untuk CV Indojaya

\section{KESIMPULAN}

Penggunaan Kerangka Kerja COBIT 4.1 Sebagai Hasil Evaluasi Pengelolaan Teknologi Informasi yang dilakukan pada perusahaan masih berada di level 2 yaitu Repeatable level dengan nilai 2.046, dalam artian bahwa perusahaan sudah menerapkan beberapa kebijakan didalam internal perusahaan. Tingkat efektifitas proses didalam instansi mempunyai karakteristik seperti; practiced, documented, enforced, trained, measured dapat lebih ditingkatkan lagi. Product requirement dan dokumentasi perancangan harus selalu dijaga agar dapat mencegah perubahan buruk yang tidak diinginkan.Belum maksimalnya pengelolaan manajeme proyek dan sumber daya teknologi informasi yang ada.

\section{SARAN}

Nilai kedewasaan pada tiap proses dalam 4(empat) domain pada COBIT 4.1 agar mendapat perhatian dari CV. INDOJAYA untuk meningkatkan pelayanan terhadap pelanggan, terutama pada proses-proses yang dirasa masih di bawah tingkat kedewasaan yang diharapkan. Hasil penelitian ini diharapkana dapat menjadikan acuan CV. INDOJAYA lebih memperbaiki dalam melakukan Tata kelola teknologi informasi berdasar COBIT 4.1 secara berkala, agar selalu dapat di hitung peningkatan yang terjadi dalam setiap evaluasi yang dilakukan.

\section{DAFTAR PUSTAKA}

[1] Andry, J. F. 2016, Audit Tata Kelola TI Menggunakan Kerangka Kerja COBIT pada Domain DS dan ME di Perusahaan Kreavi Informatika Solusindo, Seminar Nasional Teknologi Informasi dan Komunikasi, (Sentika), 287-294.

[2] Wijayanti, W Setiawan, R A Sukamto. 2017, "Performance Assessment of IT Governance with Balanced Score Card and COBIT 4.1 of Universitas Pendidikan Indonesia”, IOP Conf. Series: Journal of Physics: Conf. Series 812012072

[3] Fenny, Johanes FA. 2017, Audit Sistem Informasi Menggunakan Framework COBIT 4.1 pada PT. Aneka Solusi Teknologi, Seminar Nasional Sains dan Teknologi, UMJ

[4] Carolina, I., 2015, Analisa Penilaian Maturity Level Tata Kelola TI Berdasarkan Domain DS dan ME Menggunakan Cobit 4.1, Seminar Nasional Inovasi dan Tren (SNIT) 
[5] IT Governance Institute. 2007, COBIT 4.1 Framework, Control Objectives, Management Guidelines, Maturity Models, Rolling Meadows, IL 60008, USA: IT Governance Institute.

[6] Surbakti, H., 2012, Managing Control Object For IT (Cobit) Sebagai Standar Framework pada Proses Pengelolaan IT-Governance dan Audit Sistem Informasi, Vol. VII Nomor 19, Jurnal Teknologi Informasi ISSN: 1907-2430.

[7] Andry, J. F., Christianto, K., 2018, “Audit Menggunakan Cobit 4.1 dan Cobit 5 Dengan Case Study”, Teknosain, Yogyakarta

[8] Sihotang, H. T. 2015, Penerapan Tata Kelola Teknologi Informasi Dengan Menggunakan Cobit Framework 4.1 Studi Kasus pada PT. Perkebunan Nusantara III Medan (Persero), Jurnal Mantik Penusa, 17(1), 1-7.

[9] Arikunto, Suharsimi. 2013, Prosedur Penelitian Suatu Pendekatan Praktik, Rineka Cipta, Jakarta.

[10] Ardianto, Elvinaro. 2011, Metode Penelitian Untuk Public Relations Kuantitatif dan Kualitatif, Simbiosa Rekatama Media, Bandung.

[11] Ma'ruf Abdullah. 2015, Metodologi Penelitian Kuantitatif, Aswaja Pressindo, Yogyakarta.

[12] Sugiyono. 2009, Metode Penelitian Kuantitatif Kualitatif dan R\&D, Alfabeta, Bandung. 